\title{
The economics of integration of DVB-S with terrestrial technologies and the role of dynamic bandwidth management
}

\author{
Dimitris Katsianis $^{\mathrm{a}}$, Dimitris Varoutas $^{\mathrm{a}, *, \dagger}$ and Vassiliki Apostolopoulou ${ }^{\mathrm{b}}$ \\ ${ }^{a}$ Department of Informatics and Telecommunications, University of Athens, Panepistimiopolis, Ilissia, \\ Athens GR 157-84, Greece \\ ${ }^{\mathrm{b}}$ Temagon, Greece
}

\begin{abstract}
SUMMARY
This paper presents the technoeconomic aspects of network solutions based on integration of satellite and terrestrial, based on ADSL, WLAN and DVB-T technologies, architectures. Following a discussion of the general deployment context, the business case framework is described in terms of areas served, services offered, tariffs, demand assumptions, as well as network architecture and dimensioning rules. The key cost items are presented and economic estimations are provided in the case of telecom operators, which integrate satellite bandwidth with terrestrial technologies in different area types. The evaluated business cases have shown that the satellite rental cost (airtime cost) level is one of the most critical parameter for the economic indicator of present value. Therefore, agreements with satellite operators for spectrum usage will give operators space for business opportunities and acceptable profit margins. In addition, dynamic bandwidth allocation schemes can exploit the aggregated traffic within satellite transmission, which can benefit satellite, telecom and cable operators offering entertainment on broadband business as well as new entrants in broadband business, equipment vendors, broadcasters and TV companies. Copyright (C) 2007 John Wiley \& Sons, Ltd.
\end{abstract}

KEY WORDS: digital video broadcasting; DVB; DVB-T; DVB-S; technoeconomics; network economics; bandwidth allocation

\section{INTRODUCTION}

Satellites play a major role in global telecommunications since the last four decades [1-3] and new satellite-based technologies and services have already emerged. Digital video broadcasting satellite (DVB-S) systems are used extensively in direct-to-the-home (DTH) television broadcasting, and new satellite systems are being deployed to support digital audio broadcasting (DAB) services to both fixed and mobile users. Digitization and Internet standards are the driving forces toward convergence of the underlying technologies for delivering information, communication and entertainment services to a wide range of user groups. At the same time, there is an increasing competition between delivery 'platforms' and

\footnotetext{
*Correspondence to: Dimitris Varoutas, Department of Informatics and Telecommunications, University of Athens, Panepistimiopolis, Ilissia, Athens GR 157-84, Greece.

†E-mail: arkas@di.uoa.gr

Contract/grant sponsor: EU IST program
}

Copyright (C) 2007 John Wiley \& Sons, Ltd. 
channels. For example, audio-visual services may be delivered over mobile phones, and ecommerce can take place over interactive digital TV. In addition, ownership structures are changing fast, with horizontal mergers and alliances between content players and vertical mergers among content providers, aggregators or publishers.

Furthermore, wired and wireless technologies are interacting increasingly in the marketplace. For example, wireless services already offer converged voice, data and Internet access, via cellular, satellite and fixed wireless access networks. These will compete with-or sometimes complement - fixed line broadband options such as ADSL and its successors or digital broadcasting, with greatly increased interactivity. Broadcast and telecom operators' cooperation is needed in order to provide new value added services that each technology individually cannot provide in a satisfactory manner. Such co-operation can also improve the efficiency of existing services through better utilization of spectrum and/or enhancement of real time execution.

Especially, broadcasting is quickly moved into the digitalization era as digital audio broadcasting (DAB) and digital video broadcasting (DVB) replace traditional analogue broadcasting technologies. Since the digitalization of the whole content production chain is already a reality, broadcasters, politicians and regulators are facing a challenge and change with technical, economic and political aspects [4].

$\mathrm{DAB} / \mathrm{DVB}$ offer users more advantages and possibilities than analogue broadcasting, such as better quality, more programmes and services and the option of multimedia and interactive services. This evolution is an indicator of the convergence since $\mathrm{DAB} / \mathrm{DVB}$ integrates developments from computing, telecommunications and broadcasting.

However, political, economic and technical challenges related to the type of distribution are introduced with the terrestrial mode having special problems and potentials. Therefore, the diversity of various digital radio technologies (DAB, DVB, GSM, GPRS, UMTS, etc.) that have been optimized for specific and individual services, challenges new requirements in terms of bandwidth, interactivity, symmetry, mobility, real-time and multicast communication.

Towards this direction, the EU IST REPOSIT [5] project aimed to define, implement demonstrate and validate a spectrum efficient interactive satellite DVB-S network, using real time dynamic management of the available bandwidth, for supporting a variety of heterogeneous bit rate services, like interactive TV, Internet and multimedia services. The project included the implementation, testing and validation of the overall network performance for three characteristic types of terrestrial networks: DVB-T, WLAN and ADSL, thus contributing towards the convergence of DVB-S technology with wired and wireless terrestrial networks in an integrated and seamless environment. The network used for the interconnection of terrestrial distribution nodes, have been tested, demonstrated and validated over an actual satellite. Both the downlink and uplink will be based on DVB-S technology. An overview of the REPOSIT network configuration is shown in Figure 1.

\section{MARKET ANALYSIS}

\subsection{Market segments}

Several consultants argue that TV on broadband will come from existing satellite and cable TV operators and already broadband service providers are starting to offer TV over their networks. $\mathrm{TV}$ is a mass-market service and therefore promises high revenues and profits. However, in 


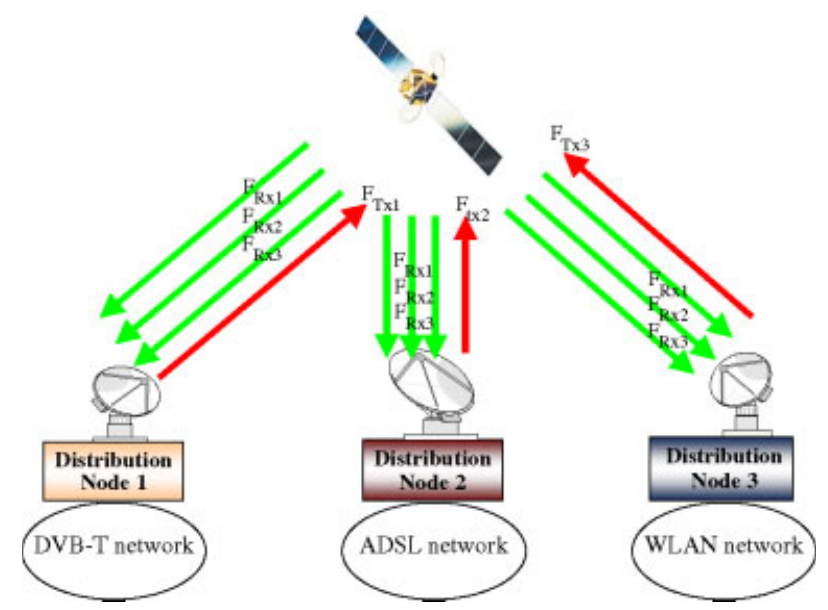

Figure 1. Overview of the REPOSIT network configuration.

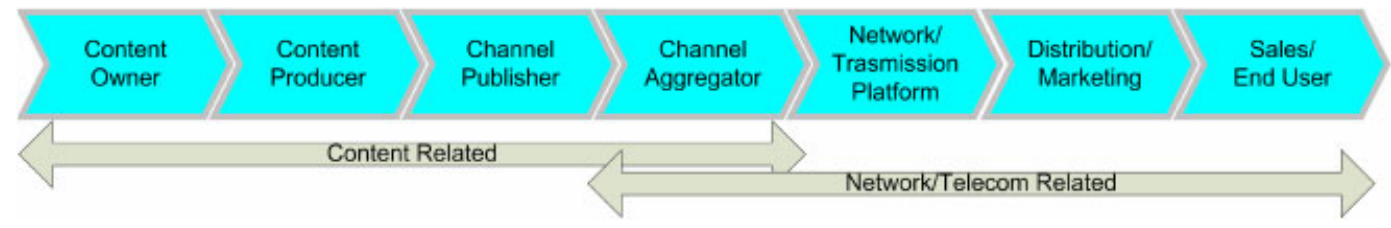

Figure 2. Value chain for TV broadband.

order to obtain a share of these revenues the broadband service provider must break into a mature market with an established value chain (Figure 2), in which the transmission network owner has so far proved to be a fairly insignificant player.

To date, the players with the power in this value chain are the content owners, since they have rights to must-watch content such as movies and sports games, and the channel aggregators who acquire the rights to distribute this content. The hurdle for the broadband service provider is to obtain access to exclusive high-value content, which is a big risk due to the high prices required and the very large customer base needed.

If the broadband provider decides to aggregate the content by its own, it has to be prepared to take the risk of a significant network investment and put a lot of effort into content acquisition, e.g. bidding for rights to sports events, etc. Another option is to resell content from other providers, but this business case is based on slim margins, which are less than $20 \%$ in many cases.

Therefore, broadband service provision relies upon the risk involved in heavily invest or form a partnership with existing aggregators from another platform or create open platforms aiming to attract third-party content providers. Due to reasons explained above, the sensible way for telecom operators to get involved in the TV business in most European markets is through partnerships or by offering an open platform for third parties.

Towards this direction, satellites can offer a broad portfolio of services that include television and radio broadcasting for the mass market, professional video broadcasting, corporate 
networking, Internet services as well as and mobile communications. Three market segments can be foreseen for satellite-based broadband services: video applications, broadband services and professional data networks.

2.1.1. Video applications. Video applications concern video transmission for direct broadcasting of TV channels and radio to cable and satellite households. For the case of Eutelsat's satellite operator, this activity represents $75 \%$ of the three market segments and it can analysed in three subcategories: broadcasting to direct-to-home antennas (DTH) and cable network; contribution services; and professional video networks that use satellite newsgathering to deliver images to program production centres and exchange television programmes between broadcasters.

2.1.2. Broadband services. Despite current developments and political decisions towards reducing the problem of the digital divide in Europe, broadband terrestrial infrastructures will not be expected to reach the majority of the European population. These developments offer business opportunities and new markets, which can be subcategorized as follows:

- Backbone connectivity for internet services providers (ISP).

- Broadband access and content delivery services for enterprises, local communities and residential users.

- Audio and video streaming to private user groups, including multicasting point-of-sale television to retailers, distribution of films to hotels and transmission of educational content.

- Tele-medicine applications aiming to interconnect remote sites with a meshed system, which uses dynamic bandwidth allocation.

- Two-way broadband networking for enterprises, residential and communities has begun to penetrate the market.

2.1.3. Professional data networks. Professional data networks are mainly operated as private point to multi-point networks using proprietary technology. These services are operated by a network of distributors who combine satellite capacity with other services to created customized solutions.

Companies operating in diversified areas of activity spanning financial, energy, retail and manufacturing sectors can use such professional data services.

\subsection{Market scenarios and business cases}

The primary research problem of any technoeconomic study for satellite-based networking, can be stated as follows:

- Can alternative terrestrial technologies be an economically viable access solution for interactive data access via satellite?

This question can be supplemented with the following three sub problems:

- What are the main business implications of such an approach?

- How dynamic bandwidth allocation schemes positioned relative to these network implementations? 
- What advantages and disadvantages from a financial point of view does dynamic bandwidth allocation address?

Such questions aim to find out whether dynamic bandwidth allocation schemes can be profitable combined with broadband access technologies. Answering this question requires mapping out the necessary network infrastructure, assessing the service types that are offered via ASDL, WLAN and DVB-T, and considering the possible key factors in determining the profitability of these technologies. These objectives are pursued through the construction and use of a robust technoeconomic model.

Such a model must be built upon an examination of convergence issues, market drivers and developments already described in previous paragraphs, which will outline the selected business cases.

Three business cases have been identified and studied hereafter.

2.2.1. Integration with WLAN providers in non-competitive areas in European countries. This business case concerns a telecom operator aiming to operate at a suburban or rural areas offering high-speed Internet access up to $512 \mathrm{kbps}$ downstream or $256 \mathrm{kbps}$. This scenario is taking into account typical examples of geographical areas from different types of European countries like Germany or France or even Scandinavian and Mediterranean countries. The maximum population of the example areas is 1500 people living in an area of $50 \mathrm{~km}^{2}$.

Different demand models and service penetration rates have been defined in order to take into account these two different offered services and revenue streams generated from traffic had been calculated.

The costs comprise service platforms and possibly middleware investments, as well as yearly expenses for capacity rental, which can be derived from the network costs, as well as commercial and customer care costs. The customer premises equipment is not taken into consideration.

It has been assumed that the users are uniformly distributed around the access points (APs) and can adopt an average of $2 \mathrm{Mbps}$ link throughput maximum. A WiFi wireless link has a maximum throughput of $11 \mathrm{Mbps}$, but this high data rate requires a high signal-to-noise ratio, thus leading to a relatively small AP coverage area [6]. It can be considered as the alternative of providing the APs with high-gain antennas to extend the coverage range. The best option for suburban or rural areas is to consider a second alternative, using recently introduced phased array antenna technology combined with beam switching to increase the range and capacity of an AP. APs equipped with these switched array antennas have a maximum outdoor line-of-sight transmission range of up to $4.2 \mathrm{~km}$ at $11 \mathrm{Mbps}$ and $7.2 \mathrm{~km}$ at $1 \mathrm{Mbps}$. Each switched array antenna covers up to $100^{\circ}$ in the horizontal plane, and up to three concurrent WiFi beams provide connections on a packet-by-packet basis with a maximum throughput per channel of $11 \mathrm{Mbps}$. Hence, both increased coverage and increased capacity are achievable [6]. The study has been restricted to WiFi $802.11 \mathrm{~b}$ (Figure 3) but nowadays other 802.11 technologies, such as $802.11 \mathrm{a}$ at $5 \mathrm{GHz}$ and $802.11 \mathrm{~g}$ at $2.4 \mathrm{GHz}$, are now standardized and available. Additional bandwidth offered by these technologies could be exploited in high demand areas (mainly urban or dense urban).

2.2.2. Integration with ADSL providers in European countries. This business case is concerning the provision of TV-channel broadcasting services via ADSL (Figure 4). The case is evaluated over two area scenarios: a large European country characterized by Germany and France, for 


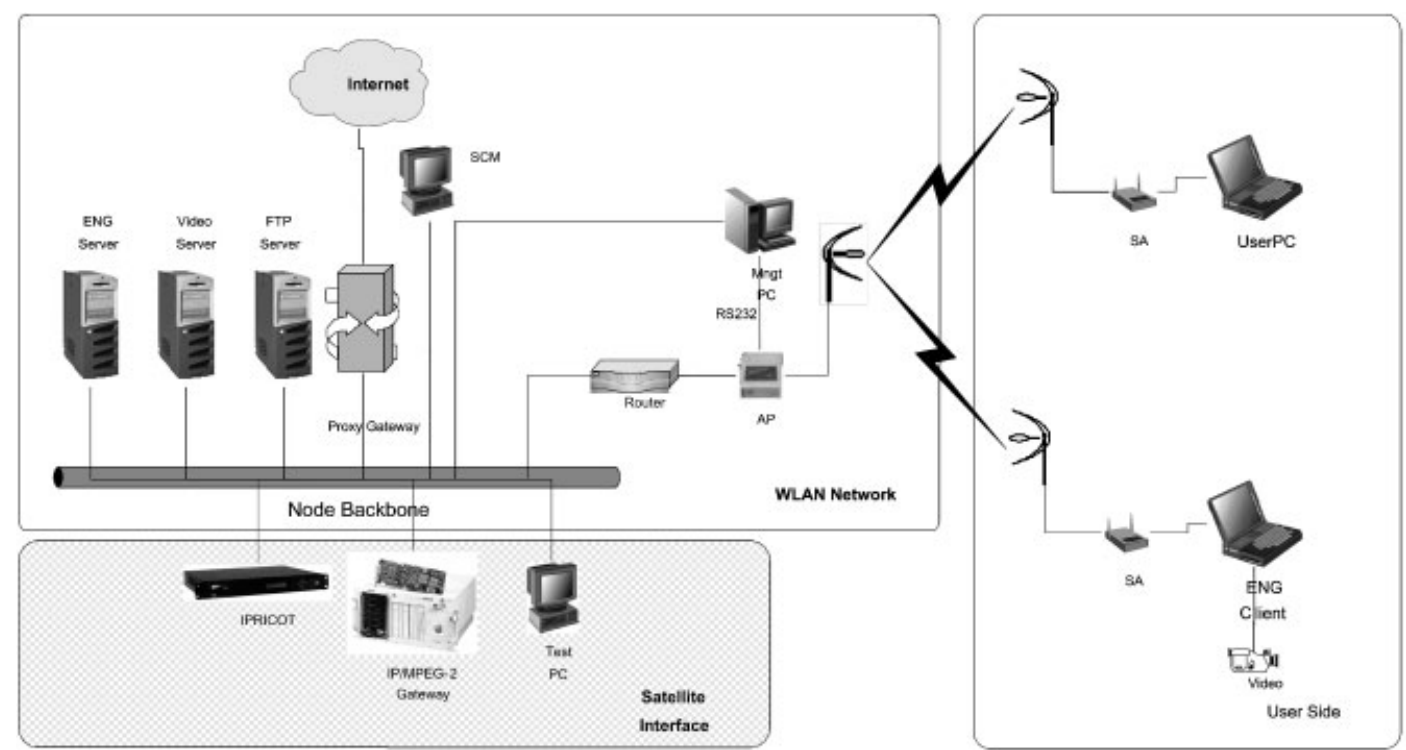

Figure 3. WLAN distribution node architecture.

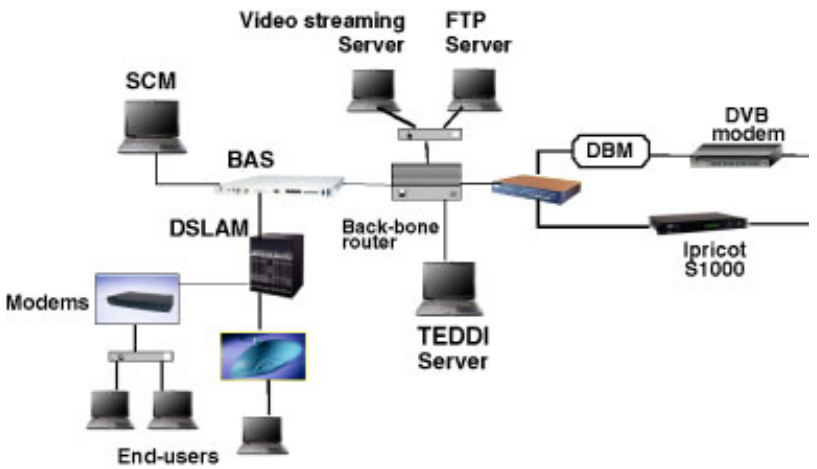

Figure 4. Block diagram of a ADSL network integrated with a DVB-S network.

example, and a small European country exemplified by Mediterranean countries like Greece (or Portugal). The country types differ on several points concerning their geographical and demographic features. In addition the subscriber Internet saturation level is estimated to be higher in the large country type - 35 versus $25 \%$ in the small country type (\% of the total population in 2012). The over subscription ration for the Internet users is assumed to be around $25 \%$. So the guarantee bandwidth for the Internet users is $75 \%$ of the total contracts granted.

2.2.3. Integration with $D V B-T$ providers. This business case concerns the financial viability of the provision of Internet channel via DVB-T interface. This case is quite similar to the small country case of ADSL business case described in the previous paragraph. The services offered, 


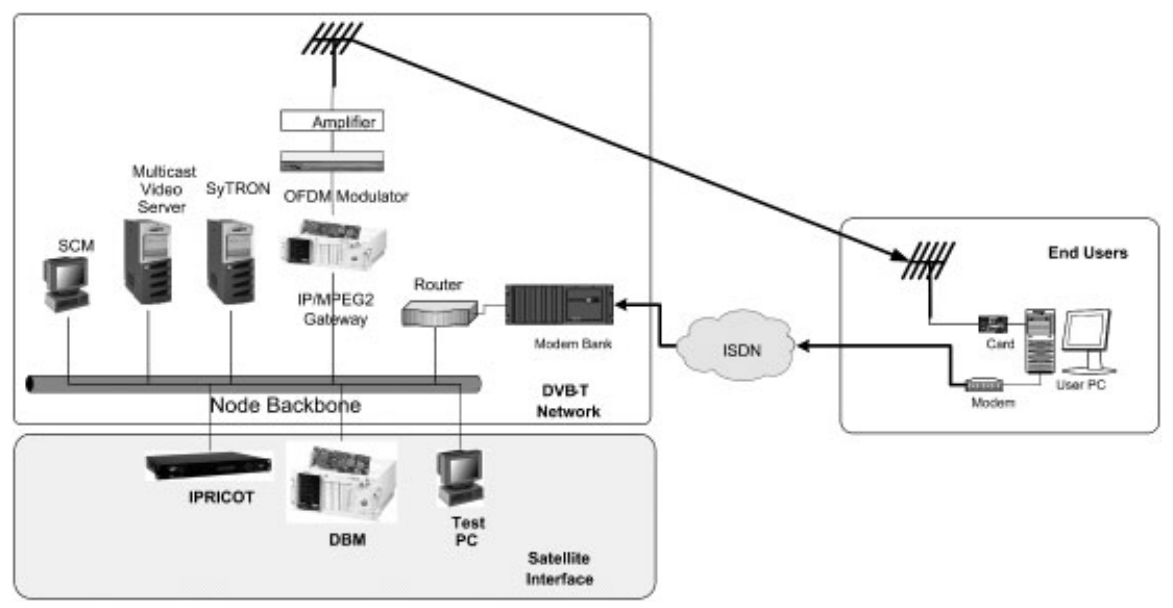

Figure 5. DVB-T network configuration.

will be Digital TV and Internet access with maximum downstream $384 \mathrm{kbps}$. The tariff is 50 euro for TV and Internet services.

It is assumed that the DVB-T access network is gradually expanded around base stations. Therefore, additional equipment such as transmitters repeaters and networks components and routers is needed in the upper layers of the DVB-T network. A basic DVB-T network is assumed to be established during the first years. This network offers sufficient geographical coverage to enable the offering of DVB-T services but finally capacity is a constrain for thins quid of network. The basic model has been evaluated in four different areas.

DVB-T services are assumed to achieve relatively modest penetration figures. In this case, the highest penetration achieved is $5 \%$ of the overall households covered (around 300000 households at the end of the study period). The end-user terminal is not included in the cost model itself (not use of the subsidization model). The main assumption about the broadcaster provider is similar to the ADSL case since the TV-Channels increase from 20 in 2005 to 40 in 2012. It is assumed that each channel in a MPEG-2 stream (2.5 Mbps) and the maximum capacity per base station is $22 \mathrm{Mbps}$ aggregate traffic.

Figure 5 illustrates the architecture that involves the distribution node backbone with the DVB-T access network facilities and shows the basic hardware needed to realize the integration between the Satellite Interface, the DVB-T access network and the Application Servers.

\subsection{Demand modelling and technoeconomic methodology}

2.3.1. Forecasting model. For the purpose of the analysis a logistic model in order to perform demand forecasts has been used. The model is recommended for long-term forecasts and for new services. To achieve a good fit, a four-parameter model including the saturation level is used. The values used are based on compilation of external reports and market surveys [7].

The model is defined by the following expression:

$$
Y_{t}=M /(1+\exp (\alpha+\beta t))^{\gamma}
$$


where $Y_{t}$ is the demand forecasted at time $t, M$ the saturation level, $\alpha, \beta$ and $\gamma$ are parameters which cannot be estimated simultaneously by ordinary least-squares regression but through a stepwise procedure in order to find the optimal ones. The saturation level $M$ is estimated, and is a fixed input to the forecasting model.

2.3.2. Country group segmentation. Two criteria were used for the country grouping: demographic/geographic and penetration homogeneity. Using three indicators: Internet penetration, broadband penetration forecast (2005) and GDP per capita, the following country groups can be formed:

- Nordic countries (e.g. Finland, Norway).

- Large central European countries (e.g. France, Germany).

- Small Southern European Countries (e.g. Greece, Portugal).

France, Germany and UK represent the large central European country group. Number of households in the three countries is, respectively, 27 million, 38 million and 26 million, while GDP per capita is about 27.000 Euro, 28.000 Euro and 24.000 Euro. At the end of 2001 the broadband penetration in France was $2.6 \%$ consisting of $2.0 \%$ DSL and $0.6 \%$ Cable modem. At the end of 2001 the broadband penetration in Germany was $6.1 \%$ consisting of $5.8 \%$ DSL and $0.3 \%$ Cable modem. At the end of 2003, the data show that the evolution of broadband will be a driver for such services.

The Southern European country group is represented by Greece and Portugal. The broadband evolution in Greece and Portugal is rather low so far. Number of households in the two countries is, respectively, 3.7 million and 5.1 million, while GDP per capita is about 1.000 Euro and 12.000 Euro. At the end of 2003 the broadband penetration in Greece was $0.8 \%$ consisting of $0.8 \%$ DSL and $0.1 \%$ Cable modem. At the end of 2003 the broadband penetration in Portugal was $3 \%$ consisting of $1.5 \%$ DSL and $1.5 \%$ Cable modem.

2.3.3. Technoeconomic methodology and economic assumptions. The techno-economic modelling was carried out using the TONIC tool, which is an implementation of the methodology developed by a series of EU co-operation projects in the field. The tool has been extensively used for several technoeconomic studies among major European telecom organizations and academic institutes [8-12].

The base of the model's operation is a database, where the cost figures of the various network components are reposited and constantly updated with data gathered from telecom operators and vendors. The output of the database is the cost evolution of the components over time. A geometrical model is used to calculate the number of network elements for the set of services and the network architectures defined. The infrastructure costs of the network are calculated using the geometric model, which involves input parameters such as subscriber density, etc.

Finally the future market penetration of these services and the tariffs associated with them, which have been calculated through market forecasts and benchmarking, are inserted into the tool. All these data are forwarded into the financial model of the tool that calculates revenues, investments, cash flows and other financial results for the network architectures for each year of the study period. An analytical description of the methodology and the tool can be found in $[8,9,13]$. 
Finally, it must be denoted that telecom operators very often resort to plain discounted cash flow when assessing their business cases. Therefore, all the selected business cases have been studied over an eight-years period, namely from 2005 to 2012 and for the calculation of the discounted cash flows, a discount rate of $10 \%$ has been selected, reflecting average values for telecom industry. Taxes have not been included since they vary among countries depending on different economic and regulatory factors.

But since this traditional approach is often unable to capture the flexibility of the decisionmakers to adapt and revise later decisions in response to unexpected market developments, sensitivity analysis has been carried out for the improvement of the analysis subject to adopted assumptions.

\section{TECHNOECONOMIC RESULTS AND RISK ESTIMATIONS}

\subsection{Integration with WLAN providers in non-competitive areas of European countries}

The main economic results for the basic scenarios are illustrated in Table I. These results show that companies aiming to operate WLAN services via a DVB-S feeder network can be benefited from an acceptable NPV (Net Present Value) and IRR (Internal Rate of Return) figures.

These figures are close to new entrants with small marker shares and therefore rather pessimistic. Surely a well-known operator with high brand-value can wait optimistic results. The investments are more or less proportional to the population for the selected area and it is based on the necessity to offer coverage. The analysis of running costs (including Operational cost) confirms estimations that the main cost is the rental cost of the required satellite channel. For the adoption of the appropriate price for the rental cost between the WLAN Operator and the Satellite provider a basic price of $134 €$ per hour for $9 \mathrm{MHz}$ has been selected.

If this is $50 \%$ more, the analysis yields to negative NPV and non-acceptable IRR and payback period. This could be the turning point for this business case and the operator must negotiate with the satellite operator/provider in order to keep the airtime costs as low as possible. Dynamic bandwidth management (DBM) can improve the capability of the satellite business owner for negotiations since it yields to an optimal allocation of the available bandwidth.

\subsection{Integration with ADSL providers in European countries}

Operators investing in TV-like services benefit from more or less the same payback period and rather interesting economic figures. The combined network including ADSL broadband access

Table I. Economic indicators of WLAN case.

\begin{tabular}{lc}
\hline Financial indicator & Value \\
\hline NPV $(€)$ & 157059 \\
IRR $(\%)$ & 14.3 \\
Rest value $(€)$ & 132376 \\
Pay back period (years) & 6.70 \\
\hline
\end{tabular}


and Interactive TV services could have larger revenues stream due to the potential biggest addressed market (Table II).

Figure 6 summarizes the additional revenues for the operation of Video and interactive TV via DVB-S platform. It can be observed that the potential revenues from the TV-like operation are more than the running and investment costs, especially after the 3 rd year of the project. In that case the investment decision of offering of such services in connection with the traditional Internet access is profitable and viable. So the integration of the TV services offer to the traditional ADSL investment project the ability to increase its project value.

But an increase in the rental cost per Mbps or technological restrictions arising from the management of the bandwidth can alter the economic figures of the business cases (Figure 7). Sensitivity analysis shows, for example, that the payback period could be delayed almost one year with a $75 \%$ increase.

In addition to sensitivity analysis, extensive risk analysis has been performed. Using Monte Carlo simulation the technoeconomic model has been recalculated for a specified number of times (trials; for example, 10.000) and a detailed statistical report that shows the entire range of possible outcomes and the likelihood of achieving each of them has been calculated.

Taking into account such an approach, it has been calculated that the possibility of having the base values (Table II) is close to $34 \%$ and the probability of having negative NPV is $24.6 \%$. This $25 \%$ is a turning point for the investors.

\subsection{Integration with $D V B-T$ providers}

For this business scenario, the case with the highest impact but also risk is the deployment in rural areas (Table II). The satellite cost represents $21 \%$ of the operational cost for this type of networks. The usage of REPOSIT-like DBM schemes, gives an advantage to the operator or

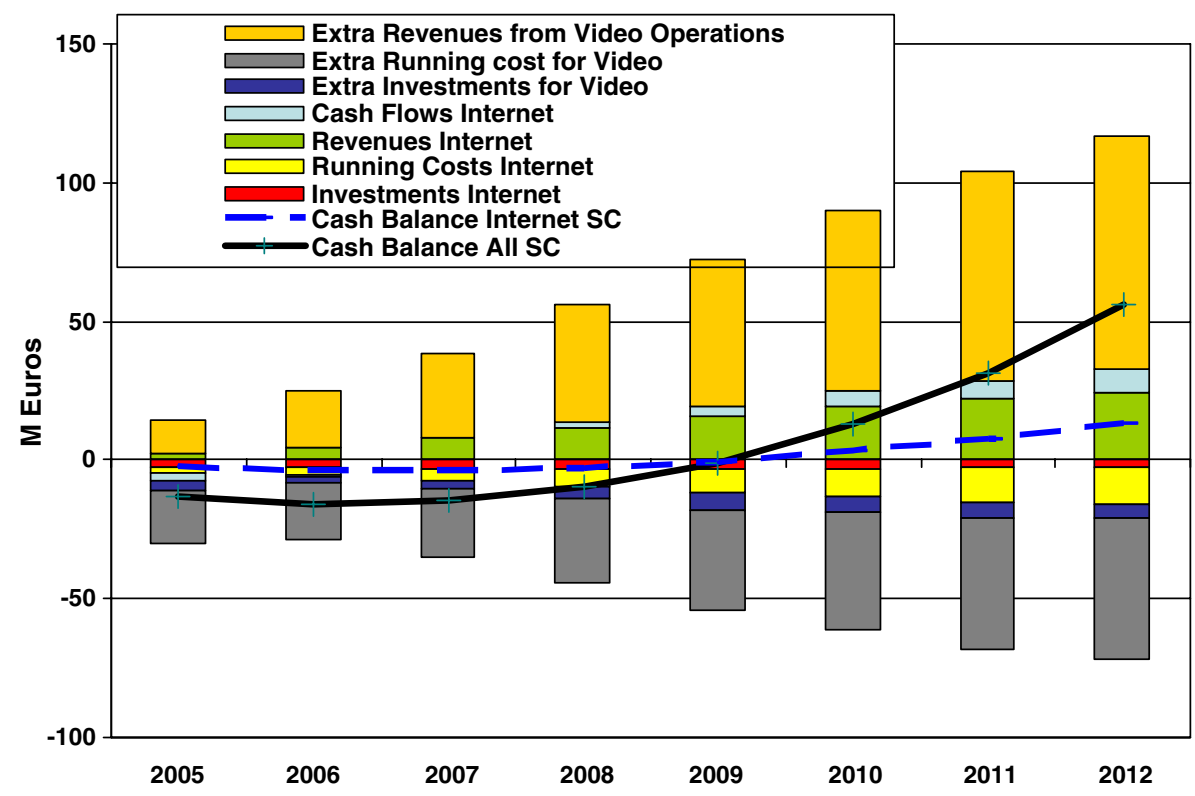

Figure 6. ADSL and video operation comparison for a small country (SC) in Europe. 


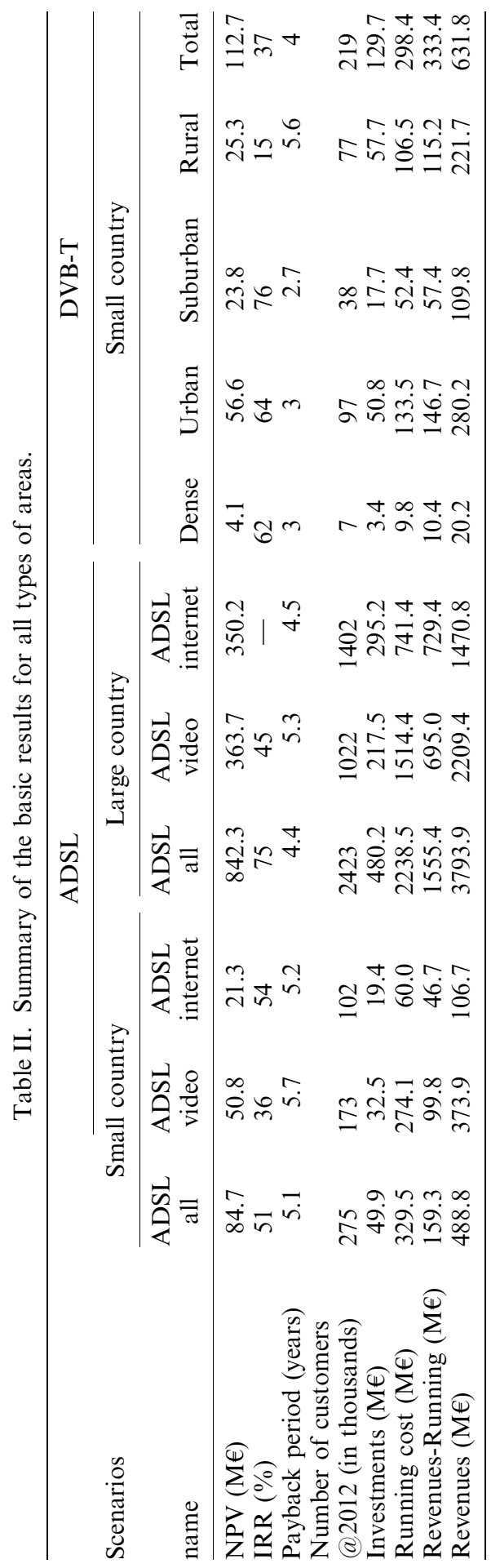




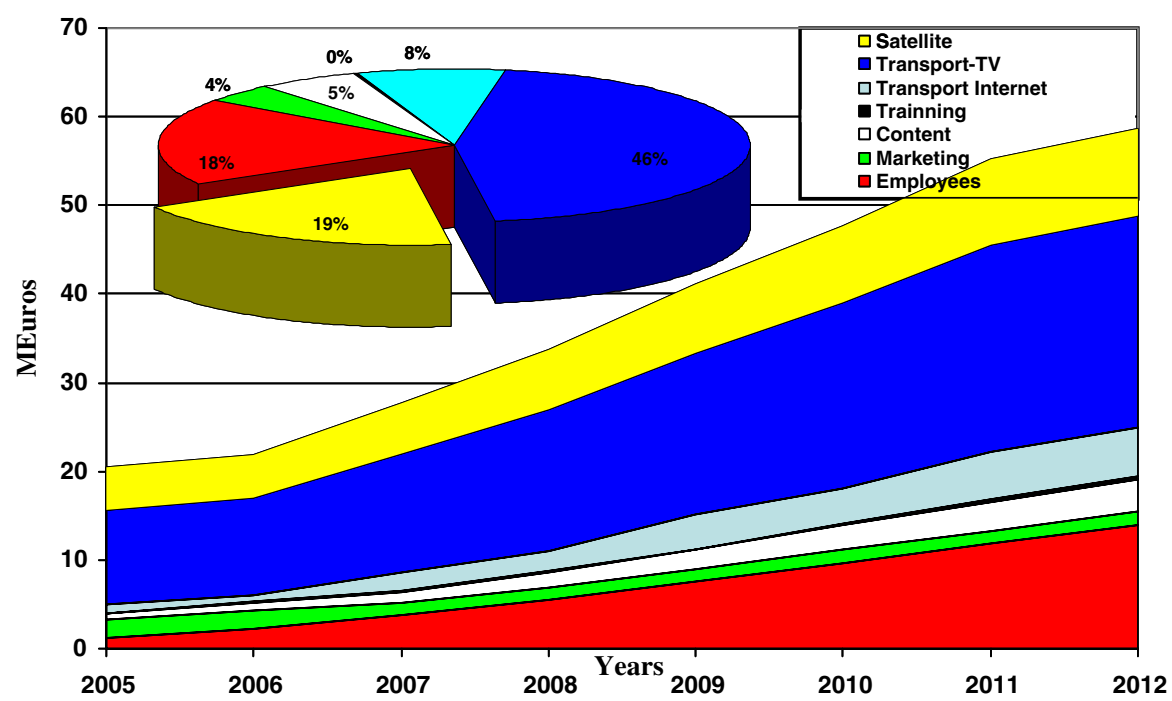

Figure 7. Breakdown of non-discounted operational expenditures (OPEX) for the case of small country. The pie chart summarizes OPEX for all years.

services provider since it decreases this cost because of offering aggregate traffic (IP services). Bandwidth management is very critical for this case since DBM can specifically control the distribution of consuming bandwidth services such as video services and therefore, offers better quality of service, which is mandatory for TV-like services. In that way more streams can be transmitted compared to normal management techniques. It has been calculated that if the operators have to pay 4 times for the required bandwidth the project results are negative.

\section{CONCLUSIONS}

The profitability of all studied architectures has been presented through specific calculations under assumptions described herein. Acceptable business opportunities can be observed through these calculations in terms of forecasted and actual digital TV and Internet penetration across Europe.

Agreements with satellite operators for spectrum usage give operators space for business opportunities and acceptable profit margins. The evaluated business case has shown that the satellite rental cost (airtime cost) level is one of the most critical parameter for the economic indicator of present value. The variation of the cost per Mbps is the determinant factor that may lead the project to be a complete failure or be 'deep in the money'. Dynamic bandwidth management solutions could improve the financial results due to optimal and flexible usage of the resources. Sensitivity analysis, used to identify the most critical parameters and the impact of uncertainties (e.g. market inputs, business agreements, etc.) show that usage and tariff levels have greatest impact, followed by the market share which is subject to marketing and business strategy.

The integration of DVB-S DBM architecture with ADSL operators aiming to provide video multicasting and video on demand services has been evaluated and profitable results and 
significant improvements have been derived in its financial indexes. But based on risk analysis results, there is a possibility $(25 \%)$ to have no profit at all if the market share and demand saturation level are below the forecasts. The message for the operator is that into a competitive environment, the preservation of a lowest acceptable market share will be difficult and precaution is mandatory.

For the exploitation of dynamic resource bandwidth schemes with WLAN operators, special market conditions with limited or no-competition must occur in order to have profitable business case in non-competitive areas and therefore these schemes can give the operator more space to negotiate the tariff level with the satellite operator.

As far as the DVB-T case is concerned, this leads to a positive prospect on the economics of all business cases in a small type country with the underline condition that $5 \%$ of the total households is covered. The cost of the satellite could turn the case to negative results but with dynamic allocation of bandwidth, this possibility is limited.

In conclusion, dynamic bandwidth allocation schemes can offer new opportunities for the TV business and the exploitation of aggregated traffic within satellite transmission can benefit satellite, telecom and cable operators which offer entertainment on broadband business as well as new entrants in broadband business, equipment vendors, broadcasters and TV companies. Furthermore, as new technologies and new services appear and broadband access becomes a reality, a viable and win-win situation for all actors can be observed for similar projects. Future work is needed towards the exploitation and evaluation of other architectures, different business profiles, service differentiation as well as risk analysis associated with different options.

\section{ACKNOWLEDGEMENTS}

Authors want to acknowledge the support of EU IST program and the fruitful comments and contributions of their colleagues in IST-REPOSIT project. In addition, they want to thank the partners of CELTIC ECOSYS project for the support of the technoeconomic tool, methodology and data.

\section{REFERENCES}

1. Giget M. Economics of satellite-communications in the context of intermodal competition. Telecommunications Policy 1994; 18(6):478-492.

2. Wright D. Mobile satellite-communications in developing-countries-the role of Inmarsat. Telecommunications Policy 1994; 18(1):5-11.

3. Tadayoni R, Skouby KE. Terrestrial digital broadcasting: convergence and its regulatory implications. Telecommunications Policy 1999; 23(2):175-199.

4. Gershon RA, Kanayama T. Direct broadcast satellites in Japan-a case-study in government business partnerships. Telecommunications Policy 1995; 19(3):217-231.

5. The EU IST REPOSIT Project. Real Time Dynamic Bandwidth Optimisation in Satellite Networks, IST-2001-34692. Available at http://www.temagon.gr/reposit/

6. Zhang ML, Wolff RS. Crossing the digital divide: cost-effective broadband wireless access for rural and remote areas. IEEE Communications Magazine 2004; 42(2):99-105.

7. Stordahl K, Kalhagen KO. Broadband forecast modelling. Evaluation of methodology and results. International Symposium on Forecasting, Merida, Mexico, 2003.

8. The EU IST TONIC Project. Techno-economics of IP Optimised Networks and Services, IST-2000-25172. Available at http://www-nrc.nokia.com/tonic/

9. The CELTIC ECOSYS Project. Techno-Economics of Integrated Communication Systems and Services. Available at http://www.celtic-ecosys.org/

10. Katsianis D, Welling I, Ylonen M, Varoutas D, Sphicopoulos T, Elnegaard NK, Olsen BT, Budry L. The financial perspective of the mobile networks in Europe. IEEE Personal Communications 2001; 8(6):58-64. 
11. Varoutas D, Katsianis D, Sphicopoulos T, Loizillon F, Kalhagen KO, Stordahl K, Welling I, Harno J. Business opportunities through UMTS-WLAN networks. Annales Des Telecommunications-Annals of Telecommunications 2003; 58(3-4):553-575.

12. Monath T, Elnegaard NK, Cadro P, Katsianis D, Varoutas D. Economics of fixed broadband access network strategies. IEEE Communications Magazine 2003; 41(9):132-139.

13. Ims L (ed.). Broadband Access Networks Introduction Strategies and Techno-economic Evaluation, Telecommunication Technology and Applications. Chapman \& Hall: London, 1998.

\section{AUTHORS' BIOGRAPHIES}

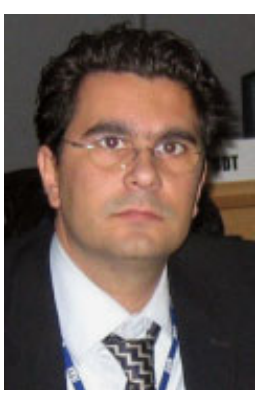

Dimitris Katsianis received the Informatics degree, the MSc in Signal Processing and Computational Systems from the University of Athens, Department of Informatics and Telecommunications. He is a research fellow with the Optical Communications Group, participating in several European R\&D projects. He has worked as an expert scientific advisor with several firms in the field of techno-economic \& network design studies. His research interests include broadband communications and methodology of network design with technoeconomic aspects. He has more than 45 publications in journals and conferences in the field of technoeconomics and telecommunication network design and he serves as a reviewer in journals and conferences.

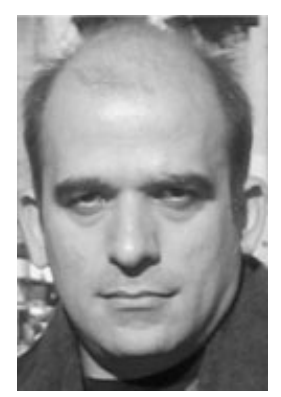

Dimitris Varoutas holds a Physics degree and $\mathrm{MSc}$ and $\mathrm{PhD}$ diplomas in communications and technoeconomics from the University of Athens. Since 2005, he is a lecturer on telecommunications technoeconomics in the Department of Informatics and Telecommunications in the same university. He has been participating in European R\&D projects since early ' $90 \mathrm{~s}$ in the areas of telecommunications and technoeconomics. He also participates in or manages related national and European activities for technoeconomic evaluation of broadband strategies, telecommunications demand forecasting, price modelling, etc. His research interests include telecommunications and technoeconomic evaluation of network architectures and services. He has published more than 45 publications in refereed journals and conferences, including leading IEEE publications. He is an IEEE member and serves as reviewer in several, including IEEE, publications and conferences.

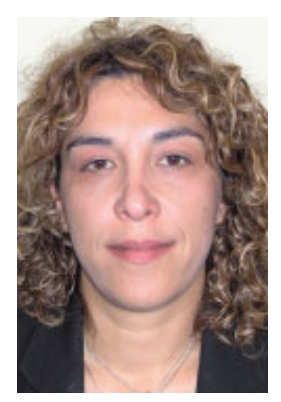

Vassiliki Apostolopoulou is a senior telecommunications expert. She received a MSc in 'Economics and Administration of Telecommunication Networks' from the University of Athens "Department of Informatics \& Telecommunications. She holds a degree from the Department of Informatics and Telecommunications in the National \& Kapodistrian University in Athens. Since 1999 she has participated in a number of Research and Commercial projects on behalf of OTE-Consulting (Temagon) as technical and administrative coordinator. Her research interests lie in the area of Terrestrial \& Satellite communications and services, broadband technologies, QoS issues for $3 \mathrm{G}$ networks and Value Added Services, and telematics. She has participated in the project management and been project manager (technical/administrative co-ordination) of a number of domestic and European research projects (IST FP5/FP6). 